\title{
Assessment of Information Sharing Using Social Network Analysis among Health Extension Workers in Konso Woreda: A Cross-Sectional Case Study
}

\section{Gilano $\mathbf{G}^{1}$, Megabiaw $\mathbf{B}^{2}$ and Alamirrew $\mathrm{A}^{3}$}

${ }^{1}$ Department of Clinical Nursing, Minch Health Science College, Arba Minch, Ethiopia

${ }^{2}$ Biostatistics and Epidemiology Department, Institute of Public Health, College of Medicine and Health Sciences, University of Gondar, Gondar, Ethiopia

${ }^{3}$ Health Informatics Department, Institute of Public Health, College of Medicine and Health Sciences, University of Gondar, Gondar, Ethiopia

\begin{abstract}
Introduction: Social network is systematic means of assessing formation and informal networks by mapping and analysing relationships among people, groups, and units of work group or even entire organizations. In this article information Sharing and problem solving methods of health extension worker in Konso woreda was assessed.
\end{abstract}

Objective: This study is aimed to assess information sharing using social network analysis among health extension workers in Konso woreda.

Methods: A cross-sectional survey was conducted on all health extension workers in Konso woreda in Southern Ethiopia, using pretested structured pretested roster type questionnaire. All analysis performed by UCINET.

Results: The response was rate 77(93\%). For who know who network: Degree (64.8), Betweenness (11.1), Eigenvector (0.11), density (79.28\%), and for information sharing network Degree (22.3), Betweenness (54.6), Eigenvector (0.11), density (27.2\%). Using MR-QAP indicated significant variables such as experience $(B=-0.041$, $p=0.0085)$, media $(B=-0.0430, p=0.0055)$, site $(B=-0.11, p=0.0005)$ and who know who $B=0.1722, p=0.0005)$. People share information have positive performance $(B=0.0466, p=0.01450)$

Conclusion: The information sharing in HEWs was inadequate. Sharing was observed among different sites rather than the same, people of different experiences than that of the same, and people who have different knowledge of Medias for information Sharing but for who know each other and have performance.

Keywords: Social network analysis; Information sharing; Health extension workers

\section{Introduction}

Sharing information across organizational boundaries is central to efforts to improve government operations and services. The central role of information and information sharing is becoming more and more evident over time, particularly as the world faces new and complex issues such as public health related issues, where borders are generally irrelevant [1].

In case of Ethiopia the issue was carried out by Health Extension Program (HEP)-a community based health service delivery professionals. The model prepared for the program assumed families who changed their health practices will change their neighbours [2]. The program includes basic and essential preventive and curative services carried out by two female Health Extension Workers (HEWs) trained and employed from the same community [3]. To know how the HEWs managed different problems a Social Network Analysis (SNA) used because it gives a rich and systematic means of assessing informal and formal networks of information sharing [4]. It shows a set of social actors and their ties [5] that provides understanding of how much information seeking is important in groups [6]. And in consulting settings, these relationships are often ones communication, awareness, trust, and decision-making [7] as researchers in this field explains, it is a process of finding hidden elements or properties through social networks [8] or discovering patterns of social inter-relationship and interaction in a population which was usually modelled with networks $[9,10]$. This might assist public health policy decisions, community enterprises and professional practices to look networked worth and aspects of works [11]. Of course other literatures also identified some primary contexts where information could be shared [12]. But, the current study was focused on relationship between the source and the recipient and recipient's learning predisposition that might increase collaboration and partnerships as important outcomes of capacitybuilding efforts [13].

Literatures more showed member of the same profession share their information in desire to improve patient care [14] and such aspects of information Sharing is also observed in portal of education where learning facilitated through Social Networking [15]. In both case, actors in different area share information for a variety purposes as those in work related environment do for patient care. It is important to understand that different interests of participants in network [16] and Perceived self-confidences were playing an important role in influencing individuals' motivation and behaviour to give information, search or to be influenced [17].

Investigators mostly assessed $\mathrm{SN}$ through centrality meaning there were the expectations that higher level of connectivity will increase access to information and give protective effect for information management

*Corresponding author: Girma Gilano, Medicine and Health Sciences, Institute of public health, P.O. Box 196, Gondar, Ethiopia, Tel: +251913930384 E-mail: girmagilano@gmail.com

Received December 17, 2016; Accepted March 25, 2017; Published April 1 2017

Citation: Gilano G, Megabiaw B, Alamirrew A (2017) Assessment of Information Sharing Using Social Network Analysis among Health Extension Workers in Konso Woreda: A Cross-Sectional Case Study. J Health Med Informat 8: 251. doi: 10.4172/2157-7420.1000251

Copyright: @ 2017 Gilano G, et al. This is an open-access article distributed under the terms of the Creative Commons Attribution License, which permits unrestricted use, distribution, and reproduction in any medium, provided the original author and source are credited. 
[18]. But in term of High centrality some individuals are function at the centre of their networks and facilitating linkages [19]. In other words there was an assumption that individuals with high centrality measure stayed in close contact with all actors. This aspect considers in degree as source for prestige and out degree as source for information [20]. In other studies, degree was a source of differences in power structure [21], even though in literary meaning degree distribution just describes the level of interaction (homogeneity or heterogeneity) [22]. In addition to this, in degree and out degree were also used to assess variance across the groups [23], so the concept of Centralization indexes explain homogeneity or heterogeneity throughout the board of information sharing [24]. But the connections for information Sharing exists in the relationships between people of different levels and coworkers or same profession [16] as the effective information Sharing depend on involved sharing media [20]. To increase communications and information exchange, it is nice to apply external forces like weekly meeting and Face-to-Face opportunities [25] that some investigator argues as it could be analyses of form, location, types of agreements and managerial practices adopted are needed for effective information Sharing [26].

In other studies sharing was not just depends on connected actors and media involved but also to whom one is connected matters more. Similarly expectation of average geographical distance was significantly negatively associated with innovation performance i.e., international contacts not matters [27] as much as information Sharing is not only for activity performance but also for self-health; i.e., isolated individual has major risk factor for illness [28]. In this case, SNA is not only the determinants but also mechanisms for inducing information dissemination [29] as usefulness of information can only be realised when it is transferred [30].

Though aforementioned concept i.e., sharing information was very important, it might not work in emergency situations where the usual ways of communicating and information exchange may not enough to bring solution unless networked [31]. Of course sharing in health professionals increase as information about that thing increase but for more beneficiaries, it should be networked so as to easy and rapid transferring [32]. In contrary, the study conducted in Portugal showed network in large sample compared their contacts, subjects do not connect very much (density=2.5\%) [33] and the one in Kentucky where network density of infection prevention staffs in hospitals is $1.8 \%$ which seems the actors might use to protect themselves by limiting their contacts in this case [34]. But in other study individual's network density is $69 \%$ that shows good interconnections, so the difference might be due to the difference in setting, and the purpose [35] which still increases something to look in our study.

Knowledge integration is the capacity to transform a public health organization's knowledge resources [11]. Here the explicit knowledge is easier to understand than implicit knowledge and share $[21,36]$ but concrete approaches to improve workers' productivity were strangely enough and even measurements for workers' performance were still lacking [37]. Literature indicate that data in the above context should be analysed network analysis methods, otherwise Standard statistical inferences based on network data are likely to be wrong [38] but as linear regression for non-network analysis (OLS), QAP approach became a workhorse in social network analysis especially for dyadic data [39]. The QAP generates a permutation distribution that is similar to the underlying distribution for which inference is drawn. Dekker and Krackhardt discussed as it could show the association between data on interpersonal relations [40] and individuals with similar characteristics were more likely to interact in most of the cases, in particular, those with similar specialties and organizational affiliations [41]. Other study in Addis Ababa uncovered as much as media of information transferring concerned there a need of more time so that the recipient and the source would be more interacted which means there are more indicators to have smooth transmission [13].

Therefore, current study outcome was more concerned social and information Sharing networks that might clear what to do to achieve more with HEWs, helps co-coordinators and planners easy way of distributing information using key nodes, and will identify informal connections than expected, which is important to rearrange the program activities.

\section{Specific objectives of the study}

1. To describe the magnitude of information sharing in health extension workers using network analysis in Konso woreda.

2. To compare information sharing and knowing each other network densities

3. To determine factors associated to information sharing among the health extension workers.

4. To empirically describe the structure of information flow among health extension workers.

\section{Methods and Materials}

\section{Study design and population}

A cross sectional study was conducted using social network analysis from February 1 to May 30, 2012, to elicit information sharing of health extension worker (community health workers). A wholenetwork approach was employed for current study because we use all of the connections between people (HEWs) in the woreda.

\section{Inclusion criteria and exclusion criteria}

All HEWs who currently working in Konso woreda were included to participate in the study. While those who were ill during time of data collection, stopped working as a health extension workers, started working when marking study population less than 6 months experience during data collection were excluded.

\section{The study area}

Konso woreda is one the many woredas in south Ethiopia where 83 health extensions works. There are 8 health centers in Konso woreda to which HEWs reports

\section{Variables of the study}

Dependent variable: Information sharing.

Independent variable: Work performance; Language of respondent; Experience of the respondent; Media of sharing information; Shared vision on the profession; Shared vision to share information; Access to share information; Number of connection among health extension workers (who know who); Other Socio-demographic variables: Age, ethnicity, Educational status, marital status, religion, experience.

\section{Study definitions}

Knowledge sharing through Social network operationalized through these concepts

Power (or Centrality): If an actor gets responses from many 
others, who in turn get many responses, the actor is at the centre of teams [30]. In other way degree of centrality is the proportion of actors that send or receive responses to or from that actor [35].

Density: Density captures how closely a group or subgroup is knit. It is a proportion that indicates the number of actual ties present in the group relative to the number of possible ties in the group [7].

Betweenness centrality: Indicates the extent to which a node lies on the shortest path between every other pair of nodes [7]

Cohesion: It is an average number of ties it takes for a person in the group to "reach" another person in the group [4].

In degree centrality: The number of times HEW was asked for information sharing.

\section{Out degree}

The way that an actor attracting, influencing others by being expert (centre for sharing).

Alter: An individual with whom another individual shares knowledge.

Social network: It is a set of social actors and the ties among them.

\section{Sociogram}

A visual diagram of a social network in which actors are represented as nodes or vertices between lines which depict connections or "ties" between actors.

Social network: It is a set of social actors and the ties among them.

Knowledge sharing: Seeking work related relevant information from others-that is related to seeking relevant knowledge from them.

Giving work related relevant information to others-that is related to providing relevant knowledge to them.

Good information sharing: in this study is having high number of connection relative to actors in the network in term of density, degree and net degree. They are measured in term of density as a cohesive network (e.g. one component with a density of $>50 \%$ ) is the richest [28].

Information sharing: Seeking work related relevant information from others, knowing that they know.

Giving work related relevant information to others, knowing that it is necessary for them.

Knowledge sharing media: the ways that serve to connect people, information and organisations through networks. Media is the ways through which people communicate in the network [7].

\section{Good information sharing}

A cohesive network is one component with a density of $>50 \%$ (the richest good network).

Information shared: Work-related relevant information exchanged, for decision, to perform daily activities, to carry out any HEWs activities.

Work performance: The achievements of the actor obtained from office to know who is sharing.

Experience of the respondent: Number of years an actor being worked if it has something to do with sharing.
Shared vision on the profession: A common reason among actors why they were sharing information. Shared vision to share information: the main reason an actor shares or wants to share information with the colleagues.

Access to share information: the possibility that an actor gets an opportunity to media available to obtain share information.

Number of connection among health: a number of actors to which a responding actor was atleast given or took information to make a decision. Data collection and procedures (instrument, personnel, data quality control).

In this study a quantitative data collection method [35] was employed with primary data collection on work-related social networks. A well-structured self-administered questionnaire was prepared to explore the impact of social networks on individual uptake and use of information by considering sharing information links.

Questionnaires: The lists of all staff working as HEWs obtained from worded health office. Using these lists, which were current lists existing at beginning of year of study, respondents were asked to check off the names of all staff members with whom they have worked or know depending on the criterion set for terms. We were also provided space for respondents to include someone who were not their staffs but a member of their network. Such tool is often called roster and/or recognition questionnaires [23]. The questions were derived from An empirical study of the role of trust in organizational setting social networks and investigating the Potential of Using Social Network, Analysis in Evaluation and the impact of social networks on information transfer in long term care facilities: protocol for a study after modification to the study setting was done [23,36,37].

Data processing and analysis: The data was checked for it completeness at field by the investigator and supervisor. Data was entered into a matrix in an EXCEL spread sheet [38] and was analysed using UCINET 6.365 Copyright (c) 1992-2011 Analytic Technologies software. A square matrix was constructed representing correlation linkages among surveyed HEWs. Each row and column labelled code for each workers and intersecting cells represented the presence or absence of co-relationship. The analysis was begun systematically with two networks: Who knows whom (WKW) and information sharing (INFOSHAR) to explore knowing each have the same pattern by sharing information, and then all determinants converted to network matrix so similar tests were performed on all together and separately. The aim of focusing these two networks was, since usually sharing information measured through density and density is the No. of connection in the network, it was to know whether this hold true the current network. All health extension workers in the Konso woreda were included so whole network principles was considered during analyses. That means the networks formed by independent variable were used to see the relation and the prediction capacity on dependent variable. The analysis has three parts. The $1^{\text {st }}$ part was descriptive statistics which describes centrality measures, the $2^{\text {nd }}$ part tested hypothesis of densities of major variables (density of who knows whom connection network and sharing information network) each with conventional parameters. In other words similarity of two networks was tested by QAP correlation and regression. The $3^{\text {rd }}$ part of analysis was Multiple Regression Quadratic Assignment Procedures (MRQAP) to predict whether relation between two actors can exist and fitting all independent variables to see their relations. All attribute data are converted to matrix by absolute different method in UCINET and then variables in the analysis are dichotomized by transformation to fit 
Citation: Gilano G, Megabiaw B, Alamirrew A (2017) Assessment of Information Sharing Using Social Network Analysis among Health Extension Workers in Konso Woreda: A Cross-Sectional Case Study. J Health Med Informat 8: 251. doi: 10.4172/2157-7420.1000251

Page 4 of 10

to the software. We analysed different indicators, such as: Number of connections (to assess sharing information density), individuals with highest number of nominations (to identify the true experts), ratio of internal to external links, the proportion of total contacts that are inward (to analyse how sought after the knowledge of the group is), and the proportion of total contacts that are outward (which units seek help the most) [27].

Multiple Regression Quadratic Assignment Procedures (MR-QAP) were performed to define predictor ties in health extension workers. MR-QAP is a combinatorial data-analysis procedure adopted routinely in social-network researches. The purpose of the MR-QAP is to regrets a dependent relational matrix on one or more independent matrices, and to determine whether independent variables are significant predictors of the dependent variables. This procedure is used to model a social relation matrix using values of other relational matrices and control variables such as attributes of social actors [39].

\section{Results}

\section{Socio-demographic characteristics}

There are a total 83 health extension workers who were included in the study and 77(93\%) were responded to the survey. HEWs that were stopped working and some who started education were unreached and the age range of the respondent was from 20-29 years. Most of the respondents were Konso in their ethnicity, educational status $10+1$, protestant in their religion, 3-4 years of work experience on average, and largely speak Konso language as first language and their media of getting togetherness was trainings and central meeting (Table 1).

\section{Social network analysis}

Knowing each other network: Number of connection that a node have on average $=64.8$. From 83 participants, one person can influence a maximum of 82 individuals except self $(0-82)$. Network Centralization; Out degree $=21.178 \%$ and in degree $=12.537 \%$ these indicates that the network was not centralized (Table 1).

The eigenvector or distance covered by each actor toward all others to be popular was $1.06 \%$, which means actors were at most peripheral. Betweenness $11.1 \%$ which showed around $89 \%$ on the ties in the network do not need mediators while the overall density of connection in this network is $79.28 \%$ which is very good.

Each code (node) represents (Figure 1) one health extension workers in the dataset and each link (edge) represents an existing connection tie among node pairs. The number of arcs (links) beginning at a node is called the out degree of the node. And they suggest connections, and in our case initiation of engagement or discourse. The number of arcs/ links ending at a node is called the in degree of the node, indicating the reception of engagement. Nodes are sized based on degree or importance and colours followed similarly. On Close observation of the graph, even though it was not centralized some key players (AMB, KAA, GRK, MSAK, TACT, GMD, SRAS, BANA, ALMA, and BRA). Except the last three codes the remaining actors were team leaders in their respective sites (place of work).

Information sharing network: All the interpretations in this Table 2 are similar with Table 1 but here Betweenness $=54.6$, centralization Out degree $=73.8 \%$ and in degree $=18.2 \%$ indicates the network was centralized. Overall density of information sharing network only $1 / 3$ or $27.19 \%$ which had an interpretation of poor information sharing connection in HEWs.

\begin{tabular}{|c|c|}
\hline Variables & N (\%) \\
\hline \multicolumn{2}{|l|}{ Demographic information } \\
\hline \multicolumn{2}{|l|}{ Age in year category } \\
\hline$<20$ & $5(6.5)$ \\
\hline $21-30$ & $68(88.3)$ \\
\hline $31-40$ & $4(5.2)$ \\
\hline \multicolumn{2}{|l|}{ Marital status } \\
\hline Single & $33(42.9)$ \\
\hline Married & $39(50.6)$ \\
\hline Separated & $2(2.6)$ \\
\hline Divorced & $2(2.6)$ \\
\hline Widowed & $1(1.3)$ \\
\hline \multicolumn{2}{|l|}{ Religion } \\
\hline Protestant & $45(58.4)$ \\
\hline Orthodox & $32(41.6)$ \\
\hline \multicolumn{2}{|l|}{ Educational status } \\
\hline Diploma & $4(5.2)$ \\
\hline $10+1$ & $73(94.80)$ \\
\hline \multicolumn{2}{|l|}{ Work experience in years } \\
\hline$<1$ & $7(9.1)$ \\
\hline 01-Feb & 15(19.1) \\
\hline 03-Apr & $32(41.6)$ \\
\hline$>4$ & $23(29.9)$ \\
\hline \multicolumn{2}{|l|}{ Ethnicity } \\
\hline Konso & $63(83.1)$ \\
\hline Gewada & $3(3.9)$ \\
\hline Others & $10(13)$ \\
\hline \multicolumn{2}{|l|}{ First language } \\
\hline Konsegna & $51(66.2)$ \\
\hline Amharic & $14(18.2)$ \\
\hline Oromegna & 12(15.6) \\
\hline \multicolumn{2}{|l|}{ Reason or vision sharing } \\
\hline Since we are all in health extension profession & $52(67.5)$ \\
\hline The goal of the program cannot achieved alone & $40(51.9)$ \\
\hline We are serving the same community & $60(77.9)$ \\
\hline $\begin{array}{l}\text { I believe that it is difficult to solve daily problems } \\
\text { alone }\end{array}$ & 22(28.5) \\
\hline \multicolumn{2}{|l|}{ Media for sharing } \\
\hline Mobile phone & $55(71.5)$ \\
\hline Meting/evaluation & $53(68.8)$ \\
\hline Training & $64(83.1)$ \\
\hline \multicolumn{2}{|l|}{ How do you grade your access to information sharing } \\
\hline Narrow & $41(53.2)$ \\
\hline Medium & $35(45.5)$ \\
\hline Very high & $1(1.3)$ \\
\hline
\end{tabular}

Table 1: General characteristics of HEWs response in Konso woreda in 2012.

All the interpretations are the same as those expressed in Figure 1 but here for information share except the network dependency on central actors or key players (Figure 2).

\section{Statistical results}

The proportion of absolute differences as large as observed for WKW is more significant that means the calculated density $(0.7928)$ is far greater than the parameter at $(\mathrm{Z}=9.1210$, $\mathrm{p}$-value $=0.0002)$ so that hypothesis at least $50 \%$ is acceptable and density of connection in HEWs is greater than $50 \%$ (pare. density).

Unlike that of WKW density here the INFOSH is below the 
Citation: Gilano G, Megabiaw B, Alamirrew A (2017) Assessment of Information Sharing Using Social Network Analysis among Health Extension Workers in Konso Woreda: A Cross-Sectional Case Study. J Health Med Informat 8: 251. doi: 10.4172/2157-7420.1000251

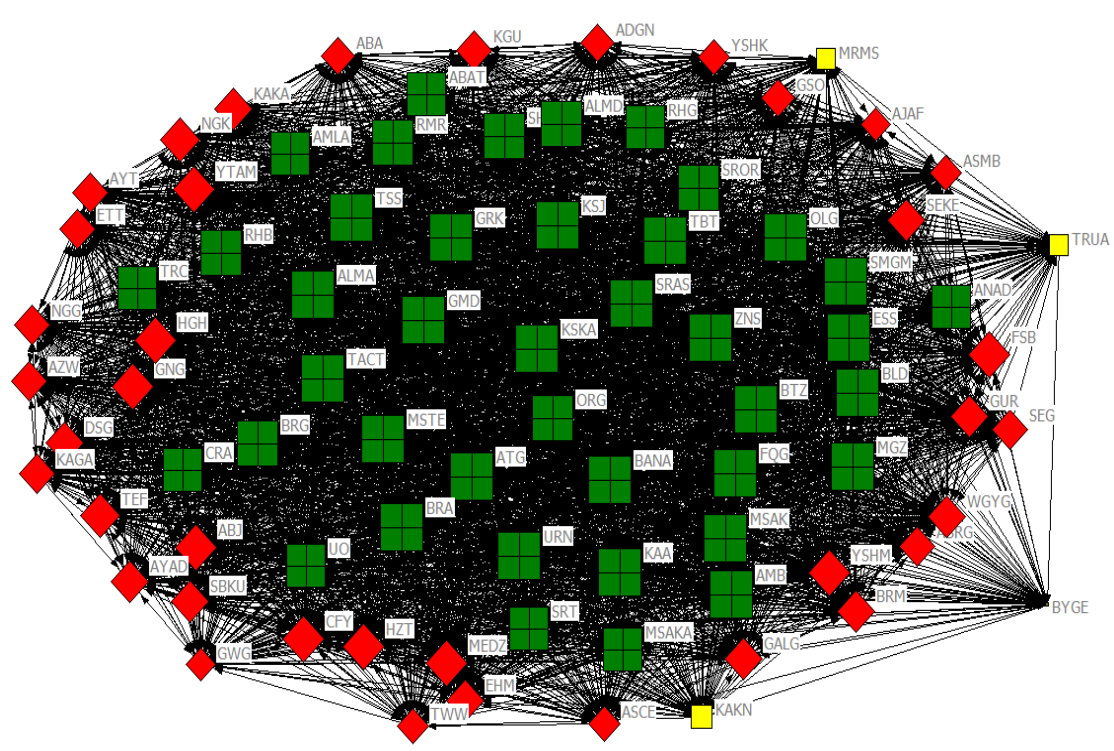

Figure 1: A network graph showing the connection among health extension workers in Konso woreda in 2012.

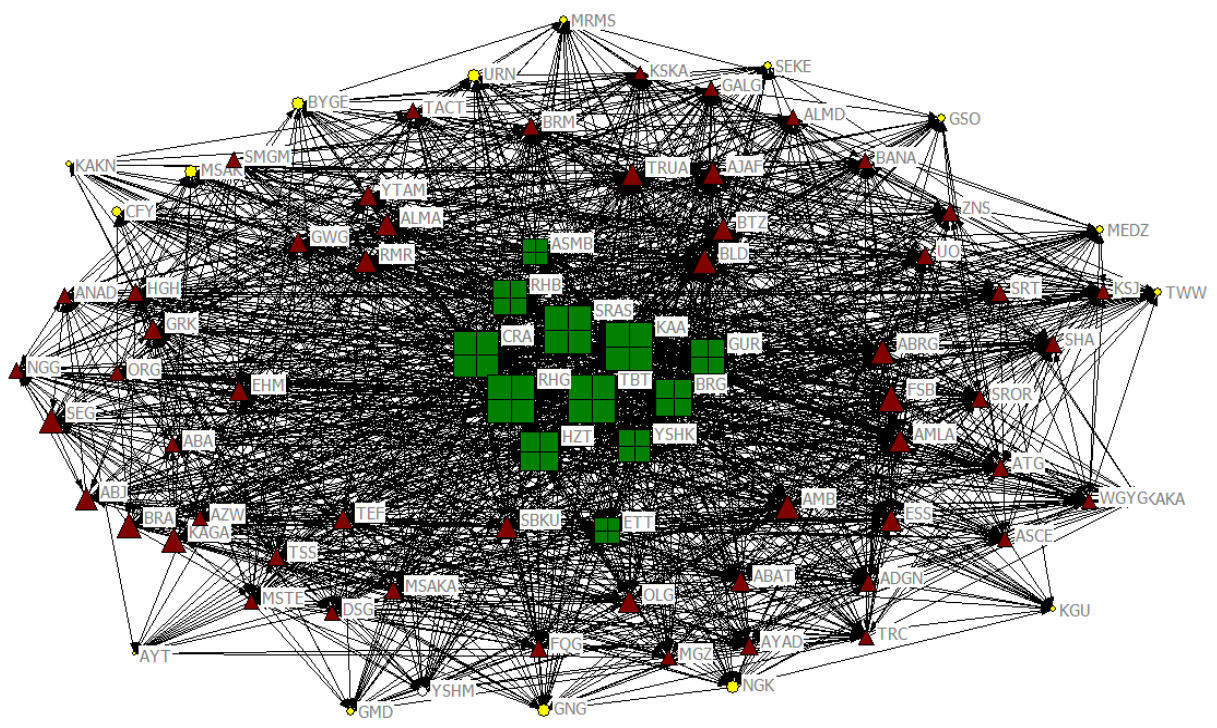

Figure 2: Network graph depicting the information sharing connection in health extension workers in Konso woreda in 2012.

\begin{tabular}{|c|c|c|c|}
\hline S. No. & Centrality measure & Mean (range) & $\begin{array}{c}\text { Centralization } \\
\text { index, \% }\end{array}$ \\
\hline 1 & In-degree & $64.8(36-75)$ & 12.5 \\
\hline 2 & Out-degree & $64.8(0-82)$ & 21.2 \\
\hline 3 & Betweenness & $11.1(0-19.8)$ & 0.13 \\
\hline 4 & Eigenvector & $0.11(0.052-0.116)$ & 1.1 \\
\hline 5 & Density & $79.28 \%$ & \\
\hline 6 & No. of achieved connections & 5382 & - \\
\hline 7 & No. of obs. & 83 & \\
\hline
\end{tabular}

Number of connection that a node have on average $=64.8$. From 83 participants Table 2: Degree centrality measures of who know who network of HEWs in Konso woreda 2012. parameter density and the difference of as large as is insignificant at $(\mathrm{Z}=-8.5462$, $\mathrm{p}$-value $=1.000)$. The densities of two relations for the same actors were compared and the density of WKW is greater than the density of INFOSH (p-value $=0.0002)$.

Table 3 shows the overlapping and interdependence among all variables. Most of the variables were significantly correlated. The highest correlation occurred between knowing media and performance $(\mathrm{r}=0.778, \mathrm{p}<0.0001)$ and between knowing each other and information sharing $(\mathrm{r}=0.168, \mathrm{p}<0.0001)$. All the correlations were in the expected direction. Since most correlation coefficients were less than 0.5 multi-collinearity was not a concern while VIF was checked for this purpose. 
Multiple regression quadratic assignment procedures: It is people of different sites shares share information with each other significantly at $(\mathrm{p}=0.0005)$ and who know who is significant at $(\mathrm{p}=0.0005)$ which means those sharing information from different sites knew each other's. Media (media for information sharing) is significant at ( $\mathrm{p}$-value $=0.0055)$ that is people of different knowledge of media of information sharing or those with less knowledge of media came to those of high knowledge. Performance of each health HEWs was taken from health office and with other variables it was also significantly associated information sharing at ( $\mathrm{p}$-value $=0.01450)$. The Examination of the magnitude of standardized coefficients also enabled us to assess the relative importance of predictors. Age and ethnicity were removed from analysis because they don't affect any variable when removed or present (Table 4).

\section{Discussion}

\section{Knowing each other network analysis}

In this network, both in degree and out degrees were equal suggesting that on average each individual in the network were influenced others and influenced by others equally (equal popularity and sociability) no attraction affinity; everything varies. The variability is very high in out degree that is an indication of little influence. It starts with zero (Table 2) because from total participants, one person can influence a maximum of 82 individuals (except self). There was no actor with central advantage all actors' popularity largely varies. From literatures individuals with highest number of nominations were explained as identified the true experts [33]. This means they provide necessary information for other easily which was not in this network. Such networks are directed networks $[42,43]$.

On base of the centralization the network in and out degree centralizations were small. These indicate the network is homogeneous in term of variability from individual to individual. It confirms

\begin{tabular}{|c|c|c|c|}
\hline S. No. & Centrality measure & Mean (range) & $\begin{array}{c}\text { Centralization } \\
\text { index, \% }\end{array}$ \\
\hline 1 & In-degree & $22.3(14-37)$ & 18.2 \\
\hline 2 & Out-degree & $22.3(0-82)$ & 73.8 \\
\hline 3 & Betweenness & $54.6(0-344.4)$ & 4.42 \\
\hline 4 & Eigenvector & $0.11(0.052-0.197)$ & 15 \\
\hline 5 & Density & $27.19 \%$ & \\
\hline 6 & $\begin{array}{c}\text { No. of achieved } \\
\text { connections }\end{array}$ & 1850 & - \\
\hline 7 & No. of obs. & 83 & \\
\hline
\end{tabular}

Table 3: Degree centrality measures of information sharing network of HEWs in Konso woreda 2012

\begin{tabular}{|c|c|}
\hline Test description & Output \\
\hline Density of WKW & 0.7928 \\
\hline Parameter & 0.5 \\
\hline Z-score & 9.121 \\
\hline Average bootstrap density & 0.7832 \\
\hline Proportion of absolute differences as large as observed & 0.0002 \\
\hline Proportion of differences as large as observed & 0.0002 \\
\hline Proportion of differences as small as observed & 1.00002 \\
\hline
\end{tabular}

Proportion of absolute differences as large as observed is more significant that means the calculated density $(0.7928)$ is far greater than the parameter at $(Z=9.1210$, $p$-value $=0.0002)$ so that hypothesis atleast $50 \%$ is acceptable and density of connection in HEWs is greater than $50 \%$

Table 4: Compare density of who know who with hypothesized parameter value of HEWs in Konso woreda 2012. what was observed from in and out degree as they were the same. Thus, in knowing each other network, the distributions of network characteristics were again equal. From literature high centralization indexes were determined as higher heterogeneity across networks i.e., high variability in higher centralization indexed networks [24,43].

In the same way the Eigenvector or the sum of the geodesic distances from each actor to all others (farness) or distance needed to be covered by an actor to be very popular was very small. In Literature it was understood that the higher the eigenvector the more central become the actor and vice versa [44] this means actors were more peripheral in this network, there was no centralization tendency.

In other words, Betweenness centrality was 11.1 indicated that around $89 \%$ of the ties in the network were not needed mediators to be connected. From standard description of experts, it was concluded that in such networks, it was individual information sharing behaviour which is very vary [43].

But knowing each other network was adequately dense. This might make us to think information sharing network could dense. Because literatures explain that higher levels of connectivity increases access to knowledge and give protective effect for knowledge management [13,23]. Other similar study conducted in North Korea showed density of $69 \%$. This might be due to the reason that HEWs have to meet all workers from trainings than immigrant women of North Korea.

\section{Information sharing network analysis}

Similarly, in degree and out degree in information sharing network is small and the same on average. Of course Figure 2 concludes that there were individuals who have dominant advantage in the network which means that there was a tendency of formation collections of actors at the centre of the graph. And so some actors depend on to obtain information small that are at the centre. This is comparable with the study in Barcelona which described that for the directed network in and out degree distributions are almost identical [22].

Centralization of this network was very different especially out degree that shows high heterogeneity. It means there were very limited actors who were very popular in giving relevant information needed for HEWs that may be why the authorities should more concerned to create information sharing ways in the program as this was also revealed by coefficient of variability for out degree that was $89 \%$ concluded that HEWs were very different in out degree centralization. The result of this was clearly observed where actors coded: CRA, BRG, TBT, SRAS, RHG, GUR, KAA, HZT, RHB, and YSHK were identified occupying little central part of the graph and were most information diffusers of the team even though this is tough toss say centralized. Of course high centralization in literature seen in negative side that means, higher network centrality indicates power is in few hands, while the mutual exchanges between other members are less. When central actor left the team there will be a greater loss on information sharing [20] because the network was highly dependent on the identified key players (Figure 2).

Similarly, in degree centralization for information sharing was small describing in seeking after the information in HEWs was homogeneous has similar meaning other studies which confirms this by explaining homogeneity as it increase with centralization index decrease and the reverse is also true. In receiving the information the team is the same $[13,19,33]$. 
Citation: Gilano G, Megabiaw B, Alamirrew A (2017) Assessment of Information Sharing Using Social Network Analysis among Health Extension Workers in Konso Woreda: A Cross-Sectional Case Study. J Health Med Informat 8: 251. doi: 10.4172/2157-7420.1000251

Page 7 of 10

Betweenness (Table 3) indicates that more than half of actors in information sharing network were depended on others to be connected to another actor. This implies, there were a lot of individuals in the network who were not communicating with source of knowledge. The eigenvector was only 15 means; Even though the network is centralized the tendency of actors to toward centre is very small. In other ways except those at centre, other actors are at peripheral and HEWs acting as source of information were very small in compare to whole actors' network. Comparable studies accept this as the properties of more dependency networks even though it might be due to most actors were receiver [19-21].

In overall observation the density of information sharing network was only $1 / 3$ of the expected ties that goes in to a category of inadequate information in HEWs; and might be due to the fact that interrelation was not fairly for information sharing. When this was observed in relation to similar studies; it was greatly varied. For instance compared to the density of study done in different places: $1.8 \%$ in Kentucky USA 2011, 2.5\% in Portugal 2008, 69\% in North Korean [33,34] were among some of studies. But the difference in density still doesn't make any supervise, since density can simply intense as size of the network narrows and the opposite as it get larger although the density of around $15-20 \%$ is expected to support information sharing in a network of about 100 members [45]

\section{Statistical discussion}

Of course different studies accept information sharing density of $>50 \%$ as good information sharing density although the achievement is not this much [34]. In considering this in the current study it was insignificant for information sharing and highly significant for knowing each other network comparing to the parameter but in case we need to be very careful as knowing each other doesn't mean information sharing (Tables 4 and 5).

\begin{tabular}{|c|c|}
\hline Test description & Outputs \\
\hline Density of HEWs & 0.2719 \\
\hline Parameter value & 0.5 \\
\hline z-score & -8.5462 \\
\hline Average bootstrap density & 0.2708 \\
\hline Proportion of absolute differences as large as observed & 1 \\
\hline Proportion of differences as large as observed & 1 \\
\hline Proportion of differences as small as observed & 0.0002 \\
\hline
\end{tabular}

Table 5: Compare density of information sharing network with hypothesized parameter value of HEWs in Konso woreda 2012.
When correlation of each variables understudy checked, pairing the two networks to know whether the difference was randomly occurred, the paired t-test showed there was a significantly gap (Table 6). This means density of information sharing network is small that concluded all people who were connected to each other were not always share information rather than need additional things. This gives more emphasis on the similarity with the network analysis under section 6.2 and the conclusion could be drawn both in network analysis and statistical confirmations but understanding that too high or low density of the network was not conducive to the information sharing as comparable studies concluding the same [46].

As expected, knowing media where to share was highly correlated with work performance, knowing each other and information sharing indeed, in these highly correlated variables, we don't expect less correlation, so we accept it positively. Generally the correlation observed in Table 7 was not sufficient to concern about multi-collinearity [47], since most coefficients satisfy $r \leq 0.5$ according to Jensen and as VIF was also between 1 and 5 .

Work experience was significant associated with information sharing which of course suggests information sharing tie existed among HEWS of different experiences in lines with literatures, and explained in term of; HEWs with relatively short periods experience were going to those with relatively long periods of experience for advice. This finding is consistent with other study where number of years since graduation was negatively associated to information sharing of health professionals $(B=-0.0318 ; \mathrm{p}<0.01)$ [41]. The concept behind this is information sharing in a profession increase then become stable or lowers when every member need no more help to make decision after all. This might also be due to, either recent increase in new members or HEWs were really sharing their experiences.

\begin{tabular}{|c|c|}
\hline Test descriptions & Output \\
\hline Density of WKW & 0.7928 \\
\hline Density of INFOSH & 0.2719 \\
\hline t-statistic & 21.3561 \\
\hline Average bootstrap difference & 0.509 \\
\hline Proportion of absolute differences as & 0.0002 \\
\hline large as observed & 0.0002 \\
\hline Proportion of differences as large as observed (WKW) & 1 \\
\hline
\end{tabular}

Table 6: Paired sample t-test for the two matrixes (WKW and INFOSH) of HEWs in Konso woreda 2012

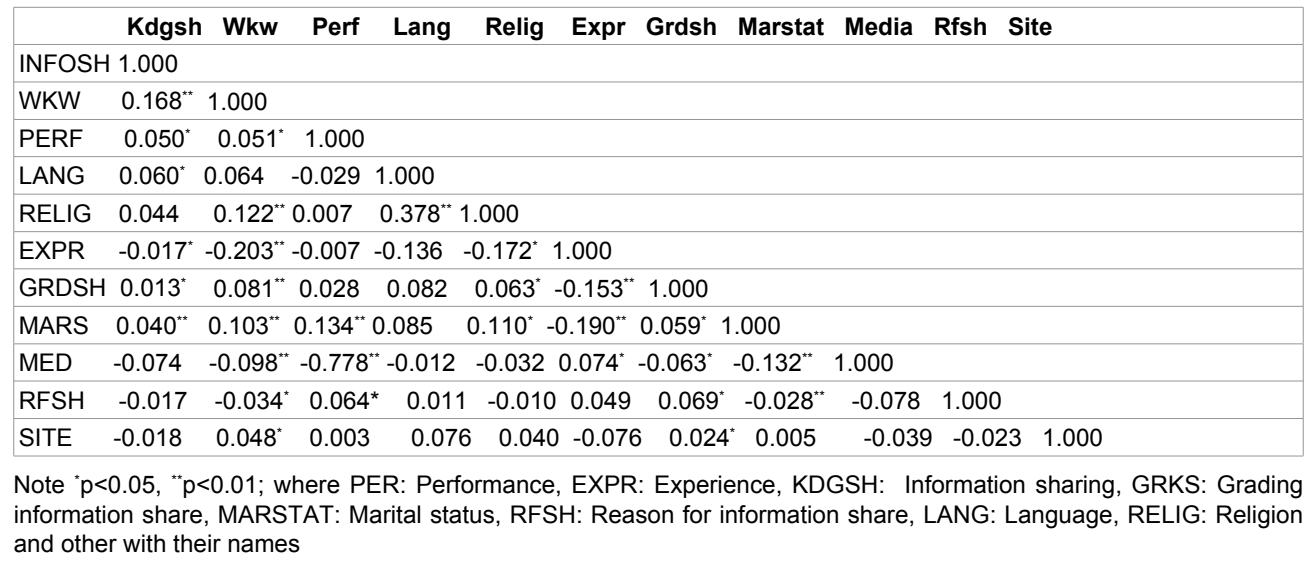

Table 7: QAP Correlation coefficients among all variables under study for HEWs in Konso woreda 2012. 
Knowledge of media connection significantly associated with information sharing. It means HEWs who have less knowledge of media of information sharing were tied with those who have good knowledge of Medias. Other studies findings suggest that, at a minimum, the informal structure supplements the formal structure in facilitating information flows [48] and knowing where to share is found very important [20]. In fact meetings usually considered as helpful for sharing information but members of low-performance described meetings as not beneficial and reported that to quit participating while high-performance staffs insisted the importance in sharing experiences. When other studies observed meeting was considered as step one to work together and share information [49]. In this case the difference might be, some HEWs were not aware of where and when to share information while those who aware were sharing to them.

It was also identified that, work performance was positively associated with information sharing consistent with literatures, of course closer relationships resulted from more frequent and more relevant information and information exchanges among high performance partners [36]. In Kentucky hospitals, it was identified that improving the efficient dissemination of information in health care professionals enhanced daily job performance [34] which the very consistent that existed in HEWs.

In current study, HEWs at Site or place of works was significantly share information which other studies went the other way meaning people who were affiliated with the same places and located in the same geographic area were more likely to collaborate share information $(B=0.0845 ; \mathrm{p}<0.01)$ [41]. The discrepancy may be due to the fact that Konso woreda is small compared to geographical area where cross sharing was enabled or the HEWs information sharing was only occur during trainings/meetings but not while they are at work place. Of course another study found that geographical distance was negatively associated to information sharing and investigators concluded that international distance don't much matter [50], but places like Konso woreda might need special consideration specifically during the current study basic network to use mobiles and internet were not available that might highly affected and limited the information sharing to meetings or training times.

Even though, knowing each other found to be significantly associated to share information and this doesn't indeed tell us sharing was that much as this can only be the baseline for information sharing. In connection to other investigations, knowing each other just mediated the effect of proximity on information seeking that when an individual know others expertise, seeking information from that individual rises [51]. Of course our finding might be due to the fact there a possibility that all HEWs might be trainee together and enabled them to know expertise and share information. Although, our study not focused the duration meeting, other studies connected information sharing mostly affected by the time duration of the trainings [13]. Thus, the information sharing of HEWs might be more improved, if recent time of trainings or staying together improved.

Access to share information is not significantly associated with information sharing but other similar studies, described that information acquisition in health care has traditionally come from many ways, like local, national, and international conferences, but those ways that are available might not be accessible otherwise accessibility is significantly associated [34]. The reason for discrepancy may be due to the difference in status of actors, difference in set ups, awareness of importance of information sharing and the fact that small HEWs were sharing information, and the fact that sharing was limited to physical connections [14].

The aforementioned fact can be more explained by the reason or the vision why HEWs sharing information was not associated with information sharing. The available references indicates that both the service receiver and provider should have a clear common vision and goals for partnership as well as a belief that their partners will not act opportunistically [33] and from other study it was also confirmed that there should be constrain that initiate information sharing [38]. Of course the difference mean a lot about why actor actual made that network. Thus more look in might be needed to know what type of information is being shared by HEWs but the understanding of constraints and the opportunity to obtain a solution might be contributed for the cut of interest to work to common vision-there is a problem you can't solve by yourself but also there is no chance to get a of your friends (Table 8).

The health extension program in Ethiopia is considered as a backbone and blood line of the whole health system in the country; it has got something to do with information sharing to get more benefit from. Although the program is such a crucial to the country population, the main actor of the program that means the health extension workers who performs in rural area where there is no references and possibly no network need to update themselves and overcome their decision making limitation by sharing information with their colloquies as in contrary, it was arguably very small in current study. Therefore the leaders and responsible people of this program should be more concerned about creating centre of information sharing so that HEWs could obtain the information that they need to make care provision decisions good as this would improve patient care. It was also found that those with more out degree were high performing workers, thus it is wise to develop a way of using main actor to improve information sharing and patient care.

Depending on this inadequate information sharing, it needs evaluation remarking this study and improves sharing within site. Activities like preparing the site report together, consulting other site and site report presentation for supervisors might be very helpful.

The more objective measure to explore actors' performance was also suggested.

\section{Authorship}

Girma Gilano wrote the proposal, participated in data collection, analysed the data and drafted the paper. Dr. Berihun Megabiaw and Mr. Atinkut Alamirrew approved the proposal with some revisions, participated in analysis. All authors participated in the preparation of the manuscript and approved the final manuscript.

\begin{tabular}{|c|c|c|c|c|}
\hline Independent & Coefficient & Coefficient & Significance & As Large \\
\hline Intercept & 0.243 & - & 0.00000 & \\
\hline Experience & -0.041 & -0.0419 & 0.0085 & 0.0085 \\
\hline Marital status & 0.0155 & 0.0171 & 0.1559 & 0.1559 \\
\hline Performance & 0.0466 & 0.0524 & 0.0145 & 0.0145 \\
\hline Media & -0.043 & -0.0466 & 0.0055 & 0.995 \\
\hline Language & 0.0206 & 0.0233 & 0.4098 & 0.4098 \\
\hline Reason for sharing & -0.015 & -0.015 & 0.1469 & 0.8536 \\
\hline Religion & 0.0207 & 0.0232 & 0.4668 & 0.4668 \\
\hline Site & -0.11 & -0.0835 & 0.0005 & 1 \\
\hline Grading Info sharing & -0.005 & -0.005 & 0.3893 & 0.6112 \\
\hline Who know who & 0.1722 & 0.1567 & 0.0005 & 0.0005 \\
\hline R-square & Adj. R. Squ & Probability & $\#$ of Obs. & - \\
\hline 0.036 & 0.034 & 0.000 & 6806 & - \\
\hline
\end{tabular}

Table 8: Factors mediating information sharing among HEWs via double Dekke semi- partial ling MR-QAP in Konso woreda 2012. 
Citation: Gilano G, Megabiaw B, Alamirrew A (2017) Assessment of Information Sharing Using Social Network Analysis among Health Extension Workers in Konso Woreda: A Cross-Sectional Case Study. J Health Med Informat 8: 251. doi: 10.4172/2157-7420.1000251

\section{Acknowledgement}

We thank the Gondar University College of medicine and health science and Konso health office for their all Supports.

\section{References}

1. Gil-Garcia RJ, Pardo TA, Burke GB (2007) Government Leadership in MultiSector IT-Enabled Networks: Lessons from the Response to the West Nile Virus Outbreak, Leading the Future of the Public Sector. The Third Transatlantic Dialogue, University of Delaware, Newark, Delaware, USA.

2. Banteyerga H (2011) Ethiopia's Health Extension Program: Improving Health through Community Involvement. MEDICC Rev 13: 46-49.

3. Kong S (2008) Capacity Project in Ethiopia: Capacity Project Country Brie series. Intra Health Int 23: 8.

4. Serrat O (2009) Knowledge Solutions: Social Network Analysis. Asian Development Bank.

5. Meltzer D, Chung J, Khalili P, Marlow E, Arora V, et al. (2010) NIH Public Access: Exploring the Use of Social Network Methods in Designing Healthcare Quality Improvement Teams. Soc Sci Med 71: 1119-1130.

6. Cross R, Parker A, Prusak L, Borgatti SP (2004) Knowing What We Know: Supporting Knowledge Creation and Sharing in Social Networks. Org Dyn 30: 61-81

7. Chen IYL, Chen NS, Kinshuk (2009) Examining the Factors Influencing Participants' Information sharing Behavior in Virtual Learning Communities. Edu Tech Soc12: 134-48.

8. Tichy NM, Tushman ML, Fombrun C (1979) Social network analysis for organizations. Acad Manag Rev 4: 507-519.

9. Tanya Y, Wolf B, Saia JA (2006) Framework for Analysis of Dynamic Social Networks. KDD 6: 20-23.

10. Prothmann TM (2007) Social Network Analysis: A Practical Method to Improve Information sharing. Stuttgart 2: 219-233.

11. Landry R, Amara N, Pablos-Mendes A, Shademani R, Gold I (2006) The knowledge-value chain: a conceptual framework for knowledge translation in health. Bulletin of the World Health Organization 84: 597-602

12. Claudia M, Norbert G, Robert L (2008) Application of social network analysis in Knowledge process.

13. Ramanadhan S, Kebede S, Mantopoulos J, Bradley EH (2010) Network-based social capital and capacity-building programs: an example from Ethiopia. Hum Resol Health 8: 17.

14. Hew KF, Hara N (2006) Identifying factors that encourage and hinder information sharing in a longstanding online community of practice. J Interact Online Learn 5: 297-316.

15. Mattes WB, Pettit SD, Sansone SA, Bushel PR, Waters MD (2004) Database development in toxicogenomics: issues and efforts. Environmental Health Perspectives 112: 495-505

16. Helms R, Ignacio R, Brinkkemper S, Zonneveld A (2010) Limitations of Network Analysis for Studying Efficiency and Effectiveness of Information sharing. Electr J Knowl Manag 8: 53-67.

17. Moshabbaki A, Jaha'nyan SE (2009) A Trust-Based Model for Information sharing In ERP Adopting Organizations. J Knowl Manag Pract 10: 1.

18. Ramanadhan S, Wiecha JL, Emmons KM, Gortmaker SL, Viswanath K (2009) Extra-team connections for knowledge transfer between staff teams. Adv Acces Public 24: 967-976.

19. Davis KE, Spielman DJ, Negash M, Aye G (2006) Smallholder Innovation in Ethiopia: Concepts, Tools, and Empirical Findings. Paper Prepared for the Innovation Africa Symposium pp: 21-23.

20. Liao K, Xiong H (2011) Study on Information sharing of Community of Practice Based on Social Network Perspective. iBusiness 3: 283-286.

21. Aviv R, Erlich Z, Ravid G, Geva A (2003) Network Analysis of Knowledge construction in Asynchronous Learning networks. JALN 7: 1.

22. Gómez V, Kaltenbrunner A, López V (2008) Statistical Analysis of the Socia Network and Discussion Threads in Slashdot. Social Networks \& Web 2-0-Analysis of Social Networks \& Online Interaction.
23. Hall JN, Moore S, Shiell A (2010) Assessing the congruence between perceived connectivity and network centrality measures specific to pandemic influenza preparedness in Alberta. BMC Pub Health 10: 124.

24. Mayo M, Pastor JC (2005) Network and effectiveness in work teams: The impact of diversity. Deposito legal.

25. Chinowsky PS (2008) A Social Network Model Analysis of Project Engineering Social Network Analysis-Project Engineering.

26. Ingram GK, Chhibber A, Elliott V, Gwin C (2003) Enhancing development effectiveness through excellence and independence in evaluation. The World Bank operations evaluation department.

27. Broekel T, Boschma R (2009) Knowledge networks in the Dutch aviation industry: the proximity paradox. cognitive science and communicative research center.

28. http://www.cmu.edu/joss/content/articles/volume1/cohen.htm

29. Sales AE, Estabrooks CA, Valente TW (2010) The impact of social networks on knowledge transfer in long-term care facilities: Protocol for a study. Implement Sci 5: 49.

30. http://www.cmu.edu/joss/content/articles/volume1/cohen.htm

31. Huang CM, Chan E, Hyder AA (2010) Web 2.0 and Internet Social Networking: A New tool for Disaster Management?-Lessons from Taiwan. BMC Med Inform Decis Mak 10: 57

32. Firestone JM, McElroy MW (2004) Doing Knowledge Management. Lear Org J 12: 1-29.

33. Marques DV, Cardoso L, Zappalá S (2008) Information sharing networks and performance. Comportamento Organizacional E Getao 14: 161-192.

34. Wiemken TL, Ramirez JA, Polgreen P, Peyrani P, Carrico RM (2011) Evaluation of the knowledge-sharing social network of hospital-based infection preventionists in Kentucky. Am J Infect Control 40: 440-445.

35. Lee B, Youm Y (2011) Social Network Effects on Post-Traumatic Stress Disorder (PTSD) in Female North Korean Immigrants. J Prev Med Public Health 44: 191-200.

36. Lee J-N (2001) The impact of information sharing, organizational capability and partnership quality on IS outsourcing success. Information and Management 38: 323-335.

37. Röll M (2004) Distributed KM-Improving Knowledge Workers' Productivity and Organisational Information sharing with Weblog-based Personal Publishing.

38. Kutzschenbach MV (2006) Organizational Learning and Social Network Structures: Case Studies of German and Norwegian Forest Sector Organizations pp: 62-180.

39. Martin JL (1999) A General Permutation-Based QAP Analysis Approach fo Dyadic Data from Multiple Groups. Connections 22: 50-60.

40. Dekker D, Krackhardt D, Snijders T (2003) Multicollinearity Robust QAP fo Multiple-Regression.

41. Mascia D, Cicchetti A, Fantini MP, Damiani G, Ricciardi W (2011) Physicians' propensity to collaborate and their attitude towards EBM: A cross-sectional study. BMC Health Serv Res 11: 172

42. Linda C, Jeremy M, Nielsen C, Judd M, Coyte PC, et al. (2009) Use of communities of practice in business and health care sectors. Implementation Science 4: 27 .

43. Hanneman RA, Riddle M (2005) Introduction to Social Network Methods: Chapter 1: Social Network Data.

44. Kilduff M, Tsai W (2003) Social Networks and Organizations. First ed. London, Thousand Oaks, New Delhi: SAGE Publications.

45. Parise S (2007) Knowledge Management and Human Resource Development: An Application in Social Network Analysis Methods. Adv Dev Hum Resour 9 359-383.

46. Thompson M (2005) Structural and Epistemic Parameters in Communities of Practice. Organization Science 16: 151-164

47. Gresov C, Stephens C (1993) The context of inter-unit influence attempts Admin Sci Quar 38: 252-276.

48. Marouf $L$, Doreian $P$ (2010) Understanding Information and Knowledge Flows as Network Processes in Oil Company. JIKM 1: 105-118. 
Citation: Gilano G, Megabiaw B, Alamirrew A (2017) Assessment of Information Sharing Using Social Network Analysis among Health Extension Workers in Konso Woreda: A Cross-Sectional Case Study. J Health Med Informat 8: 251. doi: 10.4172/2157-7420.1000251

Page 10 of 10

49. Mlis BMA, Mcinerney CR, Meese A, Orzano AJ (2008) Information sharing processes and tools in USA primary health care: analysis of four case studies.

50. Broekel T, Boschma R (2009) knowledge networks in the dutch aviation industry: the proximity paradox. Cognitive Science and Communication Research Center 17: 1

51. Borgatti SP (2003) A Relational View of Information Seeking and Learning in Social Networks. Manag Sci 49: 432-445. 